\title{
LA NUEVA FIGURACIÓN EN LA OBRA DE RAFAEL ÁNGEL FELO GARCÍA CON “TUGURIOS” (1970)
}

\author{
The New Figuration in Rafael Ángel Felo García's "Tugurios" (hovels), 1970 \\ Daniel Montero Rodríguez \\ Sede de Occidente. Universidad de Costa Rica, Costa Rica. \\ danielmont84@gmail.com
}

Recibido: 18-01-2021

Aprobado: 01-05-2021

Daniel Montero Rodríguez es Bachiller y Licenciado en Artes Plásticas con énfasis en Pintura, y cuenta con una Maestría Académica en Artes con énfasis en Artes Visuales, todas por la Universidad de Costa Rica. Actualmente labora como profesor de las carreras de Artes Plásticas de la Universidad de Costa Rica en la Sede de Occidente.

\section{RESUMEN}

Este artículo es un estudio semiótico sobre el comienzo de la nueva figuración en la pintura costarricense para la década de los años setenta; concretamente, en el trabajo del artista Rafael Ángel Felo García Picado con su obra Tugurios (1970). También, se hace referencia al contexto sociohistórico costarricense de los Salones Nacionales de Artes Plásticas (1972). Metodológicamente, se emplea un análisis semiótico, a través del proceso de interpretación del signo en tres niveles (sintáctico, semántico y pragmático). Asimismo, como acercamiento teórico, se conceptualiza la noción de "arte neofigurativo". Finalmente, se logra percibir cómo el fomento de la producción artística costarricense, que aunado a su contexto, presenta un cambio de paradigma social -crisis de valores-, debido a la aparición de la globalización y el neoliberalismo. Esto fue una influencia patente en el impulso al arte costarricense y el proceso de inicialización de la neofiguración costarricense, sobre todo en Tugurios (1970) de este pintor costarricense.

Palabras clave: semiótica; neofiguración; no-figuración; pintura costarricense; Rafael Ángel Felo García; tugurios.

\section{ABSTRACT}

This article is a semiotic study on the beginning of new figuration in the Costa Rican painting during the decade of the seventies; specifically, in the work of artist Rafael Ángel Felo García Picado with his piece "Tugurios" (Hovels) from 1970. Additionally, the socio-historical context of the Costa Rican Salones Nacionales de Artes Plásticas, or National Halls of Plastic Arts (1972) is referenced in this article. Methodologically speaking, a semiotic analysis is used to interpret the sign on three levels (syntactic, semantic and pragmatic), and the notion of "neo-figurative art" is conceptualized following a theoretical approach. Finally, it is easy to perceive how the promotion of Costa Rican art production, along with its own context, experiences a change of social paradigm (or moral crisis) due to the emergence of globalization and neoliberalism. This process of change was not only a clear influence on the promotion of Costa Rican art, but also on the initialization of Costa Rican neo-figuration. Said influence is particularly visible on "Tugurios" (1970) from this Costa Rican painter.

Keywords: semiotics; neo-figuration; non-figuration; Costa Rican painting; Rafael Ángel Felo García; tugurios (hovels). 
Revista Herencia, Vol. 34 (2), enero-junio, 2021.

\section{Introducción}

Es importante considerar la obra de Rafael Ángel Felo García dentro de la propuesta de la neofiguración costarricense, pues no es solo uno de los máximos representantes de la nofiguración (abstracción) costarricense, sino que también es uno de los precursores de una nueva figuración en la pintura del país. Asimismo, es importante considerar su obra figurativa, ya que, como refiere la estudiosa María Alejandra Triana, el artista es más reconocido por su labor figurativa posterior a la abstracción: “Desde inicios de los años setenta, el artista se dedicó de nuevo a la pintura figurativa con obras por las que es quizás, más reconocido en la actualidad: aquellas que representan tugurios o viviendas espontáneas" (2013, p. 2). Precisamente, es esa temática del tugurio con la que retoma la figuración, lo cual hace significativo valorar su propuesta como neofiguración.

Conviene recordar que Felo García no solo se dedica a la obra plástica. Sus estudios en arquitectura en el extranjero le valieron para que, junto a un grupo de arquitectos costarricenses, estructurara los planes de estudio de la Escuela de Arquitectura. De esta manera: "La Escuela de Arquitectura de la Universidad de Costa Rica abre sus puertas en 1971, con Felo García como primer director" (Alvarado, 2005, p. 24). Este hecho es relevante en la medida que el pintor logra combinar ambas áreas del saber, enriqueciendo a través del conocimiento arquitectónico su labor pictórica posterior a la no-figuración:

Es muy interesante que esta revitalización del campo arquitectónico en la vida de Felo García coincide con un cambio radical en su trabajo plástico, donde el tema arquitectónico se vuelve también protagonista en su pintura con la denominada estética del tugurio. Podemos decir que el año en que se abre la escuela de Arquitectura con Felo García a la cabeza, se inicia el planteamiento de esta temática (Alvarado, 2005, p. 26).

Por otra parte, es necesario considerar que la pintura de paisaje de Rafael Ángel Felo García tiene sus inicios mucho antes de su periodo no-figurativo, cuándo el artista apenas comenzaba a conocer y experimentar con la pintura, siendo aún estudiante de arquitectura. Esto es significativo en tanto se denota que él conocía ambas tendencias con antelación, 
Revista Herencia, Vol. 34 (2), enero-junio, 2021.

tanto la figuración como la abstracción, para luego combinarlas dentro de su propuesta temática del tugurio. Felo García tiene su primer acercamiento a la pintura cuando, a través de Teodorico (Quico) Quirós, trabaja la temática del paisaje, como expone la estudiosa del arte costarricense Ileana Alvarado:

Este encuentro es muy valioso desde todo punto de vista, pues don Quico era un pintor reconocido, con un trabajo ya consolidado y, además, con una labor como arquitecto también sólida; su pasión por la pintura, su experiencia, su generosidad y su sentido del humor, propios de la gente inteligente, lo convierten en un buen amigo y un gran apoyo para una persona joven como García. Juntos iban a pintar paisaje (2005, p. 14).

Los conocimientos previos en arquitectura, pintura de paisaje y no-figuración, en Rafael Ángel Felo García se fusionan para que en los años setenta presente su propuesta pictórica. En esta muestra una nueva figuración, donde la pintura de paisaje y la técnica expresionista logran representar el reciente paisaje urbano que se estaba dando en Costa Rica: "Es sin duda alguna Felo García el primero que se interesa en la arquitectura del tugurio como un tema digno y constante de representación pictórica. Después de una época predominantemente abstracta y no figurativa, el artista regresa a la figuración con una obra afín a su profesión de arquitecto: la arquitectura marginal urbana" (Alvarado, 2011, p. 68).

Es evidente que el proceso del artista conlleva a una nueva representación pictórica en el país. Sin embargo, no se puede afirmar que el artista desconoce del todo el movimiento neofigurativo y que, por esto, es una creación aleatoria. Por el contrario, se sabe que el pintor conocía -previo a su pintura sobre la estética del tugurio- el trabajo de neofigurativos como Fernando Botero en Colombia, incluso incursionó en el paisaje urbano de dicho país: “De Cuba pasó a Colombia para continuar jugando el mismo deporte. Aquí ya sí comenzó a dibujar con mayor constancia, enfocó su tema de interés en los tugurios de los barrios bajos de Cali, Medellín y otras ciudades. Asimismo visitó exposiciones en las que pudo apreciar la obra de artistas como Omar Rayo y Fernando Botero" (Zavaleta, 1993, p. 248). De esta manera, se puede afirmar que García había tenido contacto con la pintura neofigurativa y 
Revista Herencia, Vol. 34 (2), enero-junio, 2021.

que conocía dicho movimiento.

En este sentido, es significativo estudiar la obra pictórica de Rafael Ángel Felo García posterior a su periodo abstracto, en tanto se presenta como una nueva forma pictórica para la plástica de Costa Rica, no solo por el hecho de retomar la figuración, como menciona Alvarado, o porque logra combinar la pintura del paisaje con la técnica de su anterior expresionismo abstracto; sino por la misma temática urbano-marginal, y de referente social, característica propia de la obra neofigurativa.

La presentación del paisaje urbano La estética del tugurio ${ }^{1}$, conjunto de obras expuestas en el Banco Central en 1973, son las primeras obras en este estilo exhibida por el artista. Estas pinturas se encuentran cargadas de gran simbolismo y significación: "Las imágenes de aglomeraciones habitacionales que nos ofrece el autor desde 1973, son diversamente entendidas. Promueven en el espectador una interpretación personal, lo que hace mucho más atractiva esta temática y podríamos afirmar que esta es una de las razones por las que este arte ejerce cierta fascinación" (Alvarado, 2005, p. 34). Por tales razones, las representaciones figurativas del paisaje urbano -que permiten una gran interpretación-, son significativas para el estudio de la nueva figuración costarricense. En este sentido, dentro de este grupo de pinturas se propone la obra Tugurios de 1970, como representante de dicho movimiento para su respectivo estudio. Esta obra es parte de la colección del Banco Central de Costa Rica, es un óleo sobre madera, con unas dimensiones de 121,5 por 220,5 centímetros.

A partir de las consideraciones precedentes, se puede establecer una interrogante básica sobre el estudio de la obra del artista: ¿Cuáles son los significados que subyace dentro de la producción visual costarricense, Tugurios de 1970, de Rafael Ángel Felo García Picado como elementos del arte neofigurativo?

\footnotetext{
${ }^{1}$ En relación con el trabajo pictórico de Felo García el historiador del arte Guillermo Montero nombra a estos trabajos con dicho termino, como lo hace saber Elizabeth Barquero en el texto Felo García: artista, gestor, provocador, innovador (2005): "La "estética del Tugurio" es el nombre acuñado por el historiador del arte Carlos Guillermo Montero para definir los paisajes urbanos cuyo tema es el tugurio" (Alvarado, 2005, p. 34).
} 
Revista Herencia, Vol. 34 (2), enero-junio, 2021.

\section{Acercamiento teórico-metodológico y neofiguración}

Para una correcta aproximación analítica con la pintura seleccionada, es necesario un estudio semiótico del texto artístico, a través de los tres niveles correspondientes con el funcionamiento de los signos ${ }^{2}$. Dichos niveles se procuran en un orden lógico, coherente y gradual de la interpretación del signo en la obra: sintáctico, semántico y pragmático. Estos permiten una acertada interpretación del significante, el significado y su relación con el contexto: "El nivel sintáctico analiza las relaciones entre los signos. El nivel semántico, las cuestiones referentes al significado de los signos. El nivel pragmático, las relaciones que se establecen entre los signos y sus usuarios" (Talens, 1999, p. 47).

El nivel sintáctico permite analizar las unidades básicas de sentido dentro de la obra, es decir, el signo como significante en relación con su significado, con otros significantes y sus significados, permitiendo en su combinación un solo concepto o entendido, que funge como interpretación del texto artístico:

Dentro de este nivel se analizan las relaciones de los signos entre sí. En cuanto que los signos son entidades abstractas compuestas por el significante (clases de señales) con su significado (clase de mensaje) las relaciones entre signos podrán ser abordadas también desde una doble perspectiva: a) la combinación de entidades conceptuales (dimensión semántica) y b) la combinación de elementos de expresión que son clases de elementos perceptibles por los sentidos físicos (visual, auditivo, táctil, etc.) (Talens, 1999, p. 58).

\footnotetext{
${ }^{2}$ Charles Morris aporta un término que enriquece el estudio semiótico los elementos semióticos como significante, significado y significación, introducidos por teóricos como Saussure, Ogden, Richards y Peirce: "Un ligero desvío se advierte cuando se examina la concepción del signo que Charles Morris nos presenta en la siguiente de sus obras, Signification and Significance: A Study of the Relations of Signs and Values (1964). Aquí define la semiosis como una relación de cinco términos: el signo suscita en el intérprete la disposición para reaccionar de una forma determinada (interpretante) sobre un tipo de objeto (significación), en ciertas condiciones (contexto). Ha desaparecido el denotatum de los esquemas anteriores, y se ha introducido un nuevo elemento, el contexto" (Kowzan, 1997, p. 43). Como proponen Jenaro Talens, José Romera Castillo, Antonio Tordera y Vicente Hernández Esteve en Elementos para una semiótica del texto artístico (1999), la posibilidad de estudiar el signo en el contexto es de sumo interés para formular el estudio desde la perspectiva de un nivel pragmático.
} 
Revista Herencia, Vol. 34 (2), enero-junio, 2021.

El segundo nivel, el semántico, se relaciona con el encontrar sentido a la relación de signos en la pintura. Este es uno de los más significativos, pues no solo brinda comprensión al análisis semiológico sino que abre la posibilidad al estudio sígnico del texto pictórico:

\footnotetext{
Este nivel semántico nos es ofrecido de modo implícito por el texto mismo, en la medida en que la selección de signos, su combinación, etc. constituye un sistema de creencias acerca de la realidad que puede estar o no en contradicción con lo que explícitamente el autor asuma como suyo, pero que es, en definitiva, el campo que nos interesa para el análisis. Ya hemos dicho y repetido con anterioridad que no importa tanto lo que un artista diga que quiere decir o hacer cuanto lo que realmente dice o hace (Talens, 1999, p. 54).
}

La suma de significantes y significados, así como el hecho de generar un sentido coherente con la realidad, constituye este segundo nivel del estudio de la obra. Es decir, el nivel semántico concierne a la proporción entre la interpretación de las obras y su correspondencia con la realidad denotada en las representaciones.

El estudio sintáctico y semántico permite el entendimiento sígnico dentro de la pintura, asimismo, posibilita contrastar la obra artística con el contexto socio-cultural de los años setenta en Costa Rica. Dicha facultad es la tercera fase en el análisis semiológico, el nivel pragmático: "Dentro de este nivel se integran por una parte aquellos elementos que remiten a la relación autor/obra y a la correspondiente obra/lector, y por otra la referida al lugar de inserción de ambos, como sujetos de una práctica significante, dentro del conjunto de prácticas que constituyen una formación social" (Talens, 1999, p. 47). Por lo tanto, la contextualización de la obra con la época a la cual pertenece es significativo, ya que permite establecer la obra como texto artístico portador de sentido y, así, determinar las características fundamentales de la obra.

Por otra parte, posterior a las propuestas artísticas no-figurativas, entre los años sesenta del siglo $\mathrm{XX}$, la pintura vuelve a una re-presentacion nueva, la cual se plantea como un retorno a la figuración, pero con diferencias sustanciales que se proyectan como novedosas. En este sentido, la neofiguración como forma artístico-pictórica posterior a la no-figuración se propone, más que como un retorno a la figuración, como una tendencia de sucesión en 
Revista Herencia, Vol. 34 (2), enero-junio, 2021.

relación con su anterior producto artístico.

Para la estudiosa del arte argentino, Estefanía Tamburrino, la neofiguración es considerada como una de las tendencias que actúan sobre lo que define como Campo artístico dentro de la Escena artística, la cual se concibe como el espacio donde actúan personas e instituciones que determinan la producción del artista, como mediadores entre la sociedad y la obra (Tamburrino, 2008, p. 9). Sin embargo, la autora propone esta concepción como un elemento de ruptura, a través de un análisis de la neofiguración:

[...] la neofiguración argentina, es precisamente el de la de ruptura en las obras de arte y con ella nos referimos a un cambio evidente, a la introducción de un determinado recurso o enunciado que marque una diferencia notoria con obras anteriores y vuelvan evidentes los puntos o momentos en que la noción proyecto de vanguardia se fragiliza lo suficiente como para admitir discursos rupturistas, incluso con el propio proyecto de vanguardia (2008, p. 11).

Por otra parte, para el estudioso Marchán Fiz la nueva figuración no se puede definir o interpretar sin referenciar otras formas estéticas, siendo esto clave para interpretar otro sentido, como es el de transición que particulariza al término: "En efecto, no se puede comprender históricamente la neofiguración en sentido estricto desligada de las fuentes del informalismo" (2012, p. 23). La neofiguración no es solamente una vuelta a la figuración (como neo-ismo), sino un paso determinante después de la abstracción, depende de este para existir.

Es necesario ampliar esta percepción y, para esto, Marchán Fiz aporta el constructo teórico de elemento ambiguo, pues es interpretado desde la ambivalencia de la figurarepresentación. Para esto hace la diferencia entre representar como una mímesis y la figuración como todo tipo de arte referencial o a-referencial; sin embargo, clarifica que la figura debe ser interpretada, desde una perspectiva icónica, como esa imagen reconocible:

El término nueva figuración o neofiguración se caracteriza por su ambigüedad. El término «figura» es mucho más amplio que el de «representación». En este sentido, todo arte es "figurativo», en especial desde el punto de vista perceptivo de la oposición perceptiva clásica entre la figura y el fondo. Sin embargo, su utilización artística desde 1960 supone la relación con la forma de un objeto, es decir, 
Revista Herencia, Vol. 34 (2), enero-junio, 2021.

con la representación icónica en el sentido de la imagen. Por consiguiente, conscientes de su impresión, continuamos empleando la terminología convencional establecida (Marchán, 2012, p. 15).

En este sentido, se logra interpretar cómo el término carga con una referencia heredada, pues a pesar de que figuración es un entendido muy amplio, en relación con la nueva figuración debe ser interpretado en una perspectiva más cerrada, brindando a éste una concepción de referencialidad más concreta.

Marchán explica el proceso de figuración-representación-iconicidad con el cual se debe interpretar la neofiguración. Inicialmente introduce la relación de signo-objeto, en cuanto la obra se vuelve signo del objeto representado. En segunda instancia, la relación instaurada es icónica en tanto la obra imita al objeto. Por lo tanto, la obra neofigurativa la entiende como un signo sustitutivo. Es necesario entender esta relación icónica (obra-significante, lo representado-significado) como una relación de semejanza. Esta semejanza es variada y relativista, por lo tanto la neofiguración abarca aquellos movimientos que desde 1960 han reintroducido la representación icónica (Marchán, 2012, p. 15). Como se observa, el estudioso limita la determinación de la neofiguración a través de la contextualización temporal de la pintura, esto con el fin de restringir el amplio panorama que de estas obras se podría asimilar.

En definitiva, se debe comprender la neofiguración como esa tendencia artística de ruptura, que genera una variante significativa en el modo de representar y re-significar la representación plástica vanguardista. Pero, a su vez, se debe concebir como una tendencia contestataria, que reacciona ante un arte precedente. Si como figuración no aborda los cánones académicos de la representación, como tendencia plástica se libera de las indeterminaciones significativas de la no-figuración, siendo considerada como una transición entre un arte no-figurativo anterior y una postura estética posterior. Como revela Simón Marchán y Sarriugarte, se considera una manifestación ambigua, pues, es indeterminada al estar entre el informalismo y la representación figurativa. 
Revista Herencia, Vol. 34 (2), enero-junio, 2021.

\section{Contexto socio-histórico del inicio de la pintura neofigurativa: Salones Nacionales de Artes Plásticas}

Para el contexto de los Salones Nacionales de Artes Plásticas (1972), se observa no solo un interés del Estado y el pueblo por el arte y la cultura, un posible despertar generado por la I Bienal Centroamericana de Pintura, sino que se aúna la realidad social que se genera durante la época. La urbanización de la ciudad, consecuencia de distintos eventos políticos, económicos y sociales, termina por formar parte de las representaciones pictóricas del país.

El proceso de urbanización había iniciado para los años sesenta; sin embargo, para los años setenta, la situación en el paisaje urbano comienza a ser diferente. El crecimiento de las ciudades, la falta de planificación y la situación general del país, provocan una imagen de la ciudad poco alentadora:

La gradual conversión del Valle Central en un caos urbano había empezado. El resultado, esencialmente no planificado, es hoy en día evidente en todas partes: un universo feo, falto de parques y de facilidades para peatones y ciclistas, con el agua y el aire crecientemente contaminados. Este proceso, en curso en la década de 1970, prometía ya la pesadilla actual que es la Gran Área Metropolitana (Molina, 2005, p. 26).

La fealdad de la ciudad, de la cual habla Iván Molina, que inicia en los años setenta, implica un crecimiento urbano y, a su vez, es manifestación de los problemas económicos a los que se enfrenta el país en dicha década. Las causas de tal situación tienen sus orígenes en la relación con la región centroamericana. Los orígenes de la condición económica que empieza a enfrentar el país no solo se deben a los problemas militares que enfrentan los otros países centroamericanos, sino a su repercusión sobre la economía del mercado común en la región, así como a la recesión del mundo occidental y al endeudamiento del Estado:

El Mercado Común Centroamericano agotó su capacidad de crecimiento en el decenio de 1970, en gran medida debido al rechazo de las burguesías de los otros países del istmo a realizar reformas que elevaran el poder de compra de la población. El súbito aumento en el precio del petróleo a partir de 1973 hundió al mundo occidental 
Revista Herencia, Vol. 34 (2), enero-junio, 2021.

en la recesión, al tiempo que el precio de los productos agrícolas costarricenses empezó a caer. Esta baja fue compensada temporalmente por el alza en la cotización del café en 1976 y 1977, derivada de las heladas que afectaron la producción cafetalera de Brasil en esa época. A su vez, el Estado crecientemente solicitó préstamos a los bancos internacionales, desesperados por reinvertir los billones de dólares acumulados con el auge petrolífero (Molina, 2005, p. 35).

Estas problemáticas globales y del istmo tienen consecuencias en el país, tanto a nivel económico, político y social como en su aspecto cultural-artístico, no solo por la creación del Ministerio de Cultura, Juventud y Deportes o por las distintas reactivaciones de organizaciones culturales, como los Salones Nacionales de Artes Plásticas, sino por el mismo efecto que el impulso cultural y el desarrollo social va a tener sobre la pintura costarricense.

La reactivación de los Salones de Artes es relevante en cuanto permite contextualizar el espacio-temporal y cultural del país sobre el cual se genera una nueva pintura de carácter figurativo. Para el estudioso José Miguel Rojas, en Costa Rica son varios los sectores interesados en el apoyo cultural, como es el incentivo de la creación de los Salones Nacionales:

El Primer Salón Anual de Artes Plásticas (1972), sería convocado por el Ministerio de Cultura, Juventud y Deportes, la Dirección General de Artes y Letras y la Asociación Nacional de Artes Plásticas en pintura (óleo, acuarela, gouache, pastel u otras técnicas), dibujo, grabado y escultura. Este primer salón se llevaría a cabo en la sala de exposiciones temporales del Museo Nacional de Costa Rica a partir del 12 de diciembre de 1972 y permanecería abierto hasta el15 de enero de $1973(1994$, p. 10).

Estas representaciones que se producirían durante el periodo de los Salones Nacionales de Artes Plásticas y posterior a la I Bienal Centroamericana de Pintura, se dan desde los años sesenta, como hace saber el estudioso Iván Molina:

La década de 1960 supuso el inicio de una expansión urbana sin precedentes, que fue alimentada por inmigrantes rurales, ya se tratara de familias acomodadas, atraídas por los mejores servicios y las mayores oportunidades de estudio y de empleo público para sus hijos e hijas, o de campesinos desplazados por los procesos de concentración de la tierra, asociados con la profundización en el 
Revista Herencia, Vol. 34 (2), enero-junio, 2021.

agro. El vertiginoso crecimiento del aparato estatal (entre 1948 y 1980, se crearon unas 100 instituciones nuevas y, en el último año indicado, el 18,9 por ciento de la fuerza de trabajo del país laborando para el estado), del sector terciario y de una industrialización que fue dominada por el capital extranjero estimularon un flujo demográfico que pronto trastocó la fisonomía de la dinámica de las ciudades, sobre todo en el casco josefino ${ }^{3}(2007$, p. 4).

Por causa del proceso de migración campo-ciudad, se genera un fenómeno de crecimiento urbano que llega a tener consecuencias en la apariencia de la ciudad como en la vida de sus ciudadanos: "El costo de tal expansión urbana es muy alto en términos culturales y ambientales: aparte de una contaminación creciente, la pérdida de todo un estilo de vida" (Molina, 2007, p. 5). El aspecto de la Costa Rica de los años sesenta y setenta trae cambios provocados por las costumbres y las formas de la vida en la ciudad, estos van a verse plasmados de diversas formas en la pintura costarricense, representando cambios culturales significativos.

Para finalizar, en la década de 1970 se producen distintas acciones políticas, militares, económicas y sociales que se generan dentro y fuera del país, tanto a nivel regional como global, y llegan a afectar el arte en Costa Rica. Debido a esto, el país procura estimular una producción cultural, para instituir una sociedad más culta y que, a su vez, renueve la realidad nacional en su sentido social y artístico. Es así como surgen nuevas formas pictóricas contrarias a las pasadas y con particularidades neofigurativas como referentes del contexto del país.

\section{Análisis semiótico-pictórico de la neofiguración costarricense con "Tugurios" (1970)}

El estudio de la pintura "Tugurios" (1970), del artista y arquitecto Rafael Ángel Felo García, es significativo para el análisis de la obra neofigurativa costarricense, no solo por la propuesta de un nuevo paisaje urbano que conlleva esta, sino por su traslado estético de la

\footnotetext{
${ }^{3}$ El énfasis es propio y para fines del presente trabajo.
} 
Revista Herencia, Vol. 34 (2), enero-junio, 2021.

no-figuración a un trabajo de carácter representacional. En este sentido, interpretar la pintura Tugurios (1970) como la nueva figuración, es clave para establecer dicho movimiento en el país, asimismo, para determinar y caracterizar cómo ocurrió este proceso en la pintura de Costa Rica.

La pintura Tugurios, pertenece al conjunto de obras elaboradas por el artista a inicios de los años setenta, que demuestran su retorno a la figuración. De igual manera, estas pinturas exhiben un gran auge de formas y figuras, las cuales permiten una composición más dinámica que, unida a la incorporación de técnicas pictórica más libres -como la mancha, textura y el frotado-, posibilitan un trabajo renovado, lejos de los estereotipos de los paisajes tradicionales:

Desde el punto de vista plástico, el espacio propuesto le permite la construcción de pequeños rincones; el juego con los distintos niveles, cables de luz, antenas de televisión y ropa tendida le permite proponer una estructura compositiva muy dinámica. Como recursos plásticos sus tugurios de la primera década (setenta) son muy ricos en texturas visuales y táctiles, reducidos en el color, emplean como recurso técnico la aplicación del pigmento por frotado de un trapo y la línea que define la estructura de las casas al atravesar el color y dejar su huella incisa o algunas veces mediante un lápiz (Alvarado, 2005, p. 37).

Este tipo de composición más dinámica en la pintura, lograda con la incorporación de la figura y los recursos plásticos, muestra un nuevo paisaje; así, el aglutinamiento de casas desordenadas, como suele darse en los tugurios, es parte importante de la manera de componer del artista: "Algunas veces superpone unas casas a otras, como si se tratara de una colmena" (Alvarado, 2005, p. 37). De acuerdo con esto, es significativo valorar cómo el tipo de temática, (La estética del tugurio), así como la reincorporación de la figura (icónica) dentro de esta disposición pictórica, coaccionan un modelo de composición en la pintura, el cual se aproxima al movimiento neofigurativo, como plantea el estudioso Simón Marchán:

La neofiguración aprovechó la composición caógena, desordenada, propia del informalismo. Ahora bien, la introducción del objeto le exigía una cierta lógica de convenciones gráficas e icónicas sin las 
Revista Herencia, Vol. 34 (2), enero-junio, 2021.

cuales no podía existir como representación. La composición neofigurativa conjugó los polos de la figuración y del lugar que ocupa en el espacio (2012, p. 26).

Por otra parte, la pintura no solo ejemplifica un retorno figurativo en la obra del artista, sino que muestra la incorporación técnica que desarrolla en un periodo no-figurativo, pero aplicado esta vez a un trabajo del nuevo paisaje urbano: "Su última muestra, en 1973, tiene singular significado. Felo García aprovecha sus experiencias abstractas aplicándolas ahora al paisaje urbano. El típico ambiente de barriada josefina con sus casuchas de madera alcanza solidez plástica y expresión artística" (Ulloa, 1979, p. 137). La representación de la barriada josefina, como refiere Ricardo Ulloa, se fusiona entre la figuración y la técnica no-figurativa, generando una nueva imagen del paisaje costarricense.

Esa nueva imagen que incorpora la figuración y la experiencia abstracta de obras anteriores a la pintura, se propone como un síntoma de la introducción de la nueva figuración en la obra Tugurios. Esto se recalca cuando lleana Alvarado explica los tres componentes principales del tipo de obra: "Se generó así un nuevo tipo de paisaje urbano que, aunque partió del estudio de la realidad, es netamente pictórico, ya que el artista no se sujetó al realismo sino que generó una construcción abstracta muy personal” (2011, p. 68). Con esto, el paisaje urbano como obra netamente pictórica, a través de una construcción abstracta, caracteriza a la pintura como de tipo neofigurativo. Esto ya que, como se ha estudiado con anterioridad, ese vínculo figuración-abstracción genera en la pintura posterior a la década del sesenta un reconocimiento de esta como neofiguración.

La estudiosa del arte, Alejandra Tamburrino, al estudiar el grupo Neofigurativo en Argentina, logra establecer características propias del movimiento (en coincidencia con el trabajo teórico de Marchán), donde propone esa fusión figuración-abstracción: “De hecho, el grupo Neofigurativo ha sido revisado la mayoría de las veces destacando cierto grado innovador, especialmente en el aspecto formal, la fusión entre abstracción y figuración, la deformación de elementos y el rechazo a lo visualmente atractivo" (2008, p. 13). Al tomar en cuenta esto, así como la relación que se da en la pintura Tugurios, es posible concebirla ligada a esta 
Revista Herencia, Vol. 34 (2), enero-junio, 2021.

tendencia pictórica, perfilando de cierta manera la neofiguración en el país.

De esta manera, se visualiza cómo el plano de la expresión en la obra permite un primer acercamiento al movimiento neofigurativo. Así, al profundizar en la composición y observar las representaciones de cables de luz, antenas de televisión y ropa tendida sobre las casas, se demuestra esa reincorporación de la figura que, después del periodo abstracto, es indicio de las obras neofigurativas. Por otra parte, recursos como son las texturas visuales y táctiles, el frotado, así como la incorporación técnica del expresionismo ejercido por García y aplicado al nuevo paisaje urbano en la obra Tugurios, permiten enlazarla con la característica particular de la neofiguración; es decir, esa fusión entre abstracción y figuración.

La interpretación adecuada de la pintura Tugurio requiere conocer el verdadero significado de este título como paratexto de la obra. Por lo tanto, cuando se indaga en su definición se tiene que corresponder a: “Choza o casilla de pastores. \|| 2. Habitación, vivienda o establecimiento pequeño y mezquino" (Real Academia de la Lengua Española, tomo 10, 2001, p. 1522). En sí, el tugurio es una casa en condiciones precarias. De esta manera, el paratexto de la obra refiere inmediatamente la significación de la representación visual en la pintura. Es un barrio pobre, es un escenario mezquino.

El estudio de los símbolos en las diferentes figuras representadas en la pintura, permite estudiar el significado de las casas que se presentan en el barrio empobrecido, ese tugurio de chozas. En este sentido, se tiene que la casa maneja un simbolismo sagrado en una relación de casa-templo; sin embargo, al estudiar esta es posible establecer otro significado asociado al significado de choza:

La choza, frágil, de imagen pobre, con su techumbre hecha de hierbas, sin otro suelo que la tierra desnuda, refugio de pastores y nomadas, es símbolo de la efímera existencia humana. Pero sólo es vista así por quien tiene sus ojos puestos en el más allá. De hecho, mucha literatura acude a la choza para verla llena de seres monstruosos, de peligros insospechados o de fantásticos tesoros que 
Revista Herencia, Vol. 34 (2), enero-junio, 2021.

guardan al héroe, quien siempre resulta victorioso. Es el lugar de la lucha iniciática (Deneb, 2001, p. 249).

De tal forma, el grupo de casas-chozas, como símbolo de la efímera existencia humana, como ese lugar de lucha, aunado a elementos representados como cables de luz, antenas de televisión y ropa tendida (como refiere la estudiosa lleana Alvarado en la pintura de tugurio), esos pequeños rincones empobrecidos, se pueden interpretar como isotopías del mismo significado de la lucha que se genera en medio de la pobreza. Es un lugar de resistencia, donde la pobreza se representa como paisaje urbano-marginal.

En este sentido, es posible confirmar esta relación simbólica entre referente, significante y significado, pues, como explica la estudiosa del arte costarricense lleana Alvarado, la pintura de este tipo se interpreta como crítica social:

Es de esta manera que el artista, a partir de un tema surgido en los años 70 por un problema real de la Gran Área Metropolitana, convirtió el tugurio en un planteamiento pictórico de carácter abstracto y generó, sin buscarlo, una crítica social en un paisaje urbano que, no obstante el caos de los tugurios en la realidad, era armónico en la representación. El artista e investigador guatemalteco Roberto Cabrera expresó muy bien la forma en que García sintetizó, en imágenes, la realidad percibida, de lo que él llamó la “cultura de la pobreza” (2011, p. 70).

Con esto Alvarado logra sintetizar la relación del signo en la pintura de paisaje urbano del artista. Entonces, se posibilita interpretar que Tugurios, como significante, es una pintura figurativa de carácter abstracto, la cual refiere a la realidad costarricense, en cuando representa un tema surgido en los años 70 por un problema real de la Gran Área Metropolitana. Por otra parte, también permite comprender el significado de la obra como cultura de la pobreza. Asimismo, esto permite observar en la pintura un carácter de crítica social.

Parte de lo que interesa al estudiar una obra visual, según un análisis sígnico, no es la relación obra-pintor (no interesa qué dice el pintor), sino la relación obra-espectador (qué 
Revista Herencia, Vol. 34 (2), enero-junio, 2021.

dice la obra), permitiendo interpretar el trabajo pictórico en su contexto inmediato ${ }^{4}$. Por lo tanto, es relevante señalar algunas valoraciones, que se han realizado al tipo de obra, sobre la estética del tugurio, como la que presenta Alvarado sobre el criterio de la escritora Carmen Naranjo:

Arte comprometido con la crítica social, eso es lo que Carmen Naranjo piensa al admirar las obras que obtuvieron el Premio Nacional de Pintura en 1973. Para mí era la denuncia social más grande que se había hecho en el país, y me asombró la plasticidad, la belleza, el mensaje; como había Felo combinado esas tres cosas, incluso los blancos que usó para dar la idea de soledad, desamparo y abandono de ciertos sectores sociales, cuando pintó montañas de tugurios, pirámides de tugurios, el mismo blanco da la sensación de grupos aislados, abandonados, desolados (Alvarado, 2005, p. 35).

Es relevante observar cómo, para Carmen Naranjo, la pintura del nuevo paisaje urbano refiere a un compromiso con la crítica social. Esto demuestra que la significación del paratexto y las relevancias simbólicas de las representaciones en la obra, consiguen tematizar un concepto sólido y unitario.

Por otra parte, es necesario considerar aspectos presentes en la pintura como son el blanco del fondo, la ropa tendida o el gris de las casas (chozas); estos son presentados por Alvarado cuando le brinda un énfasis al blanco, en las representaciones de Rafael Ángel Felo García:

\footnotetext{
Es indudable que en la solución plástica de García el blanco (luz) cobró protagonismo a nivel simbólico, pero es importante aclarar que este valor se potenció gracias a las decisiones formales tomadas por el artista. A nivel formal el blanco es fondo y forma (representación). Por un lado, como fondo da la
}

\footnotetext{
${ }^{4}$ Parte de este planteamiento es propuesto por Michel de Foucault cuando explica: "La noción de obra primero. Se dice, en efecto (y una vez más es una terrible tesis muy familiar), que lo propio de la crítica no es poner de relieve las relaciones de la obra con el autor, ni querer reconstituir a través de los textos un pensamiento o una experiencia; más bien tiene que analizar la obra en su estructura, en su arquitectura, en su forma intrínseca y en el juego de sus relaciones internas" (2010, p. 56). Asimismo, Roland Barthes expone sobre el estudio de una obra: "(...)pero existe un lugar en el que se recoge toda esa multiplicidad, y ese lugar no es el autor, como hasta hoy se ha dicho, sino el lector: el lector es el espacio mismo en que se inscriben, sin que se pierda ni una, todas las citas que constituyen una escritura; la unidad del texto no está en su origen, sino en su destino, pero este destino ya no puede seguir siendo personal(...)" (1987, p. 71). De esta manera, el estudio de una obra se presenta prioritariamente sobre el texto (texto-visual) y sobre el lector (espectador), para conseguir una interpretación correcta de sentido.
} 
Revista Herencia, Vol. 34 (2), enero-junio, 2021.

sensación de espacio abierto, en oposición al gris de la arquitectura (sombra). Por otro lado, como forma -representación de ropa tendida- se convierte en el contrapunto ideal para contrarrestar el peso producido por el gris aglutinamiento de las casas (2011, p. 69).

Al estudio sígnico que se ha realizado de la choza se le aúna ahora el del color; como presenta Alvarado, las casas por aglutinamiento generan un gris que contrasta con el blanco del fondo y de la ropa tendida. Al profundizar en la simbología del gris, se incrementa ese significado que ofrece tanto el paratexto de la pintura como las representaciones figurativas en este. Esa cultura de la pobreza que refiere la estética del tugurio se ve recalcada con el cromema con que es representada; en este sentido, al estudiar la simbología del color, se tiene que: "El gris, por ser resultado de una mezcla a partes iguales, es como el cetro de un equilibrio, pero siempre es visto como el color de cierto halo de pesimismo, cuando no de ambigüedad" (Deneb, 2001, p. 239). De esta manera, ese barrio pobre como escenario de mal aspecto, en tanto constituye la estética del tugurio, se ve reiterado simbólicamente con el color gris con que es representado.

Por otra parte, Alvarado expone otro color relevante para el estudio de la obra. La estudiosa interpreta el blanco como elemento y principio artístico que presenta no solo un juego figura-fondo (blanco del fondo y figuras grises), sino que equilibra la composición al incorporar la ropa tendida blanca, como forma de compensación de pesos visuales. Asimismo, si se estudia el blanco como cromema en Tugurios, es posible connotar una relación simbólica metonímica ${ }^{5}$ :

La representación del hombre aparece de una manera tácita en la obra pictórica del artista. En los tugurios, el inquilino está representado por las casas mismas, las antenas de televisión, las puertas y las ventanas abiertas por las que escapa la luz, la ropa tendida; todo ello nos asegura que el hombre

\footnotetext{
${ }^{5}$ La metonimia es entendida como un desplazamiento de sentido, donde el significante refiere a otro tipo de significado, desplazando su significación; pues esta es: “Consideramos metonimias pictóricas a aquellas operaciones en las que una magnitud sustituye a otra manteniendo con ella una relación de contigüidad (causa-efecto, continente-contenido, portador-cualidad, parte-todo-sinécdoque) (Carrere y Saborit, 2000, p. 307). Con esto, es posible comprender un significado diferente al significante, en el cual el sentido es desplazado a otro significante con el que mantienen alguna relación -contigüidad.
} 
Revista Herencia, Vol. 34 (2), enero-junio, 2021.

es el actor principal, que construyó y habita estos lugares, que está presente pero no lo vemos (Alvarado, 2005, p. 39).

Así, es posible observar cómo ese desplazamiento del significado donde el mismo tugurio es signo del hombre, permite estudiar la obra como un referente social en relación con lo que anteriormente se presentaba como crítica social. Este tipo de estética no es solo signo del hombre, sino que está vinculada con el propio crecimiento de la sociedad: "A nivel de significación, la proliferación de ropa tendida blanca evidencia el creciente número de habitantes de la barriada" (Alvarado, 2011, p. 70). Con esto, es posible afirmar que la obra no solo significa, sino que también denota metonímicamente al hombre y, de esta manera, se comprende cómo connota una relación social.

El estudio de los significados de la pintura Tugurios, así como en general sobre la obra pictórica de Felo García, posibilita considerar dicha obra como un germen social, pues representa la realidad costarricense de los años setenta; asimismo, la significancia del trabajo pictórico, en tanto estética del tugurio-cultura de la pobreza, refuerza su clasificación como una obra de carácter social. Esto, a su vez, hace factible interpretar la obra como de naturaleza neofigurativa, dado que las características generales de esta tendencia estética tienen un interés primario en el ser humano y su entorno; como expone el estudioso Simón Marchán Fiz, la neofiguración presenta la reintroducción del ícono tímidamente, sin embargo:

Paulatinamente se fue enriqueciendo de connotaciones explicitas, referidas a realidades sociales concretas. Basta señalar la temática humana aislada inicial y la tematización posterior de unidades iconográficas, de temas con mayor fuerza simbólica y participativa en el seno de las diferentes sociedades. La explicitación de connotaciones repercutió de un modo inmediato en los niveles pragmáticos de las relaciones de las obras con los espectadores (2012, p. 19).

Esta perspectiva de la nueva figuración, en la cual se retoma al ser humano y su entorno, no solo plantea la posibilidad de re-presentar al ser humano, sino que permite proyectar una realidad social donde se observa la existencia de éste, su agonía, sufrimiento; es decir, es 
Revista Herencia, Vol. 34 (2), enero-junio, 2021.

más cercana a las realidades sociales de su contexto, de forma similar como actúa la representación tácita (metonímica) del hombre y su realidad empobrecida en Tugurios.

Ante estas relaciones simbólicas entre el hombre y su contexto-espacio, también es posible observar una neofiguración del paisaje. Esto se consigue al estudiar una realidad latinoamericana del movimiento de la nueva figuración; tal planteamiento es propuesto por la estudiosa del arte venezolano Nidia Tabárez Reyes, en Esbozo histórico del arte de representación de paisajes en Venezuela desde principios hasta finales del siglo XX (2009), donde expone que, con el surgimiento de la neofiguración en Venezuela, se abre camino a la reinterpretación del nuevo paisaje: “En la década de los 70, los artistas interesados por retomar el género paisajista, no escaparon a tales intereses y por ello surge en estos años inquietudes de acercamiento hacia la naturaleza y hacia el interior del ser (una vuelta hacia sí mismo). Se ha despertado en ellos una necesidad de investigación y reflexión" (p. 100). Como se puede observar, en la realidad latinoamericana se brinda una perspectiva del paisaje como parte de ese nuevo movimiento de los años sesenta y setenta, donde se retoma la realidad del ser humano (interior del ser). Esto, a su vez, se enlaza con lo que está aconteciendo en Costa Rica, en el mismo momento histórico, donde Tugurios es la representación del surgimiento del nuevo paisaje urbano, cargado de crítica social.

Hasta este momento, el estudio sígnico como plano del contenido de la pintura permite esbozar un mismo significado, al contemplar elementos como las chozas y las otras representaciones, que se interpretan como isotopías de la misma temática de la pobreza. Este nuevo paisaje urbano marginal se contempla como un signo de crítica social. Asimismo, el análisis de cromemas como el gris y el blanco refieren a esa cultura de la pobreza y al entendido metonímico del hombre y su crecimiento desmedido (ropa tendida). Esta significancia en Tugurios hace factible interpretar esa tematización general de pobreza (esa efímera existencia humana, esa precariedad), que se puede vincular con la neofiguración por su interés: la angustia, el miedo, la soledad del ser humano; en cierto modo se enfoca también en la crítica social. 
Revista Herencia, Vol. 34 (2), enero-junio, 2021.

Por otra parte, esa relación contextual de la pintura en estudio con la realidad del país, es factible de corroborar cuando se indaga en lo acontecido durante la época cuando fue realizada la obra. En este sentido, es posible observar cómo la introducción de nuevas ideologías en el país, así como las consecuencias del neoliberalismo y los procesos de globalización, comienzan a hacerse sentir en el entorno costarricense, sobre todo al verse vinculado a la integración en el Mercado Común Centroamericano. De esta manera, el escenario del país cambió paulatinamente durante este periodo:

La primera fase de la expansión urbana, entre 1960 y 1980, se caracterizó por una ampliación de las comunicaciones y los transportes que facilitó el contacto entre la capital y sus comunidades circundantes [...] a lo largo de las principales vías de acceso al casco josefino florecía una urbanización, en la que confluían viviendas con comercios, talleres y fábricas, un universo sin áreas verdes apropiadas, ruidoso y con aire cada vez más contaminado (Molina, 2007, p. 4).

Con esto es posible comprender cómo la pintura Tugurios llega a representar esa estética del tugurio que menciona el historiador del arte Guillermo Montero. No solo es la ampliación de la ciudad y su posterior afeamiento, sino el mismo proceso de migración campo-ciudad que intensifica este crecimiento urbano. Así, como explica Alvarado, ese incremento urbano -relativo al crecimiento de la población- se ve representado en la pintura mediante la proliferación de ropa tendida blanca. Esto es desarrollado por Felo García al observar la realidad del barrio josefino, el cual es un fenómeno tanto nacional como latinoamericano:

En 1973. Un 57 por ciento de los costarricenses vivía en el Valle Central, y fue recompensado por ello con una cantidad desproporcionada de infraestructura y servicios públicos. Como en muchas partes de América Latina, el eje del crecimiento urbano fue más la expansión del sector terciario que la industrialización, aunque esta última experimentó una transformación decisiva a partir de 1960 (Molina, 2005, p. 26).

Un ejemplo de este proceso urbanístico y de cambio social en otras partes del continente, es expuesto por la estudiosa del arte venezolano Nidia Tabarez, quien plantea que los 
Revista Herencia, Vol. 34 (2), enero-junio, 2021.

problemas sociales tienen que ver con los procesos de industrialización presentados desde los años sesenta, así como el desplazamiento de los habitantes a las ciudades, generando problemas de carácter social: "Ya el paisaje urbano en los 60 había sido invadido por la industrialización; carreteras, automóviles, televisores, electrodomésticos, envuelven la vida del hombre. Hay una movilización de habitantes del campo a la ciudad y surge, como consecuencia, el auge de la marginalidad, la delincuencia y la miseria" (2009, p. 99). Estos cambios no son exclusivos de países suramericanos; es necesario recordar que, entre los años sesentas y setentas, dos tercios de la inversión pública de Costa Rica se destinó a la construcción de puentes y carreteras, puertos y caminos, represas y otras plantas eléctricas; por otra parte, la televisora en el país inició en la década de los sesenta, así como la conversión del Valle Central en un caos urbano (Molina, 2005, p. 17-26). Todo esto generó una variación tanto en el paisaje costarricense, como en su respectiva pintura de paisaje.

De esta manera, es posible observar cómo los significantes representados en la pintura Tugurios, como el aglutinamiento de chozas, el color gris de estas, así como los cables de luz, antenas de televisión y ropa la tendida, son referentes inmediatos de la realidad del paisaje costarricense, un paisaje cada vez más urbano. Por otra parte, la obra se convierte en un significante de la realidad social del país, a través de significados como pobreza, pesimismo, efímera existencia humana. En consecuencia, tanto la obra en estudio como el trabajo pictórico posterior a la no-figuración en García, se interpretan como crítica social porque representan el contexto socio-histórico del país.

Parte de esa forma como la obra contextualiza la realidad costarricense de los años setenta, se presenta luego de realizada la pintura (1970), cuando se registran datos históricos que corroboran parte de lo que la obra manifiesta; por ejemplo, al estudiar que la proliferación de ropa tendida blanca evidencia el creciente número de habitantes de la barriada, esto llega a ser registrado cuando: “...en 1977, unas 500.000 personas (casi la cuarta parte de la población total del país en ese año) viajaban diariamente al casco capitalino. La subordinación de los cantones colindantes con el josefino pronto amplió su cobertura geográfica, y alcanzó las ciudades de Alajuela, Heredia, y los entornos de cada una (Molina, 
Revista Herencia, Vol. 34 (2), enero-junio, 2021.

2007, p. 5). La migración campo-ciudad, así como el incremento de la población y la geografía urbanas, son condiciones representadas (de modo tácito o metonímico) en la obra Tugurios, por lo cual la obra se establece como un referente social.

Ese proceso de migración de los costarricenses a la capital, debido en parte a las facilidades que brindaba la ciudad, así como por los procesos de concentración de la tierra que desplazaba a los campesinos, se ve representando en la obra del artista -como ya se mencionó de manera tácita-, a través de la aglomeración urbana. Esto es justificado por Ileana Alvarado cuando explica:

Es fundamental anotar que el espacio abierto de la primera propuesta de la Estética del Tugurio, cedió el paso a la proliferación de la arquitectura en la segunda, ilustrando -sin buscarlo adrede- lo que sucedía en la realidad, donde las migraciones a las ciudades grandes aumentaban y con ello los problemas de trabajo y vivienda. Así como la pobreza se extendía cada vez más en la realidad, ampliándose con ello el nuevo paisaje urbano, en los trabajos de García también los tugurios comenzaron a llenar todo el espacio pictórico (2011, p. 72).

Según lo anterior, es posible observar que los problemas de trabajo, vivienda y pobreza, se asocian con las migraciones a las ciudades y el creciente urbanismo. Esto queda registrado -de modo progresivo- en las representaciones de Rafael Ángel Felo García. De esta manera, es posible inferir que la pintura Tugurios es el testimonio de los primeros cambios generados en la oleada de paisaje urbano-marginal. Si bien el número de casas en esta obra es reducido -dado que es una de las primeras en el estilo de la estética del tugurio y por lo tanto, no llega a ser una hipérbole visual ${ }^{6}$ de lo que llegarán a ser las posteriores pinturas de paisaje urbano-, sí consigue referir la problematización de vivienda y pobreza que se estaba generando en la realidad costarricense de su época.

\footnotetext{
${ }^{6}$ Este concepto debe ser comprendido como lo explican Alberto Carrere y José Saborit al referirse a las Figuras y tropos, en este apartado asimilan la Hipérbole Visual como una exageración (de tamaño) en la figura representada en determinada imagen: "La hipérbole visual se caracteriza por un exceso -de aumento o disminución- en el plano de la expresión, que desborda los límites de la verosimilitud en la representación icónica o las expectativas respecto a la regularidad plástica. Su exageración -asistida con frecuencia por tropos, como la metáfora- permite reconocer, no obstante, su lejano parecido con un significado verosímil” (2000, p. 443). De esta manera, es el cambio en la proporción del icono representado lo que varía la significación del signo expuesto en la imagen.
} 
Revista Herencia, Vol. 34 (2), enero-junio, 2021.

Por otra parte, como ya se mencionó anteriormente, no es de interés la opinión del artista sino la interpretación que se recoge al estudiar la pintura. En este sentido, es posible observar cómo la obra es producto, en parte, de la influencia profesional de García (Arquitectura). Sin embargo, la referencia que genera la representación del barrio pobre es incuestionablemente contextual, pues si bien el interés del artista es la solución del problema habitacional de la población de escasos recursos (Alvarado, 2005, p. 37), la denotación del tugurio connota significados de pobreza y urbanismo desordenado:

Roberto Cabrera Padilla afirma que la formación profesional de Felo García pesa en la escogencia de la temática, pero es claro en asegurar que no lo interpreta como una conceptualización plástica teñida de psicologismo denunciador. Sitúa esta manifestación artística como logada al ambiente sociocultural costarricense, a la cultura de la pobreza, en los años setenta, producto de las movilizaciones del campo a la ciudad de los que surgen las áreas marginadas y los enjambres habitacionales pobres en todos los espacios vacíos o deteriorados de San José, incluidas las casas de cartón y desechos bajo puentes y pendientes movedizas de los ríos Torres y María Aguilar que enmarcan la ciudad capital (Alvarado, 2005, p. 34).

Al estudiar a profundidad la pintura Tugurios, es posible establecer que la obra referencia esa idea de cultura de la pobreza de la que han hablado varios de los estudiosos, mediante el desarrollo de la estética del tugurio realizada por el artista. Todo esto representa la realidad costarricense que se desarrollaba en la década de 1970. Por otra parte, es necesario entender qué sucedía en el acontecer nacional que permitió este tipo de relación obracontexto.

La pintura en estudio se realizó cuando el país se enfrentaba a las consecuencias de la migración campo-ciudad, como resultado de los procesos de concentración de tierra; a su vez, esto llevó al empobrecimiento del pequeño agricultor, generando el aumento del precarismo en los alrededores de la ciudad capital, y llegando a manifestarse en la estética del tugurio dentro de la representación pictórica. Esta situación específica es explicada por el estudioso Iván Molina: 
Revista Herencia, Vol. 34 (2), enero-junio, 2021.

En contraste con los pequeños y medianos caficultores, que se movilizaron exitosamente en 1960 con el fin de regular mejor su relación con la burguesía cafetalera, el descontento entre los campesinos pobres se expresó, en algunos casos, en la formación de ligas y comités de orientación izquierdista. El total de familias precaristas se elevó de 14000 a 17421 entre 1963 y 1973, y entre 1963 y 1970, estallaron 2203 conflictos por la tierra, la mayoría en el pacífico Norte y Sur y en Limón (áreas en las que se expandió la ganadería y el cultivo del banano) (2005, p. 31).

Esta situación de pobreza y precarismo en aumento durante los años setenta, era apenas el comienzo. Los habitantes de estos espacios empobrecidos eran esos campesinos desplazados quienes, en busca de una mejor situación de vida, migran a las ciudades y, en estas, solo generan los conocidos tugurios sin llegar a solucionar sus problemas:

Los tugurios de la realidad hoy, no se parecen a los de los primeros tiempos, donde muchos de los habitantes eran campesinos que, en búsqueda de mejores condiciones de vida, encontraron la miseria; pero que, no obstante, a pesar de la estrechez, vivían en un ambiente relativamente más seguro, donde posiblemente la ropa se podía colgar en el exterior de la casa (Alvarado, 2011, p. 74).

Es evidente cómo la pintura Tugurios representa no solo la estética del tugurio como manifestación del paisaje urbano, sino que es la representación contextual de la historia de Costa Rica. En este sentido, es posible observar que la pintura representa esa temática de la cultura de la pobreza, generando una interpretación de crítica social; asimismo, posibilita el estudio de la realidad del país en la década de los setentas. Todo esto a través del nuevo paisaje urbano costarricense.

Dentro de esta estética del tugurio, que se enmarca dentro del nuevo paisaje urbano, es posible estudiar la obra en relación con la temática y las representaciones de obras neofigurativas, sobre todo con la estética neofigurativa venezolana. En este sentido, como establece la estudiosa de la neofiguración venezolana Nidia Tabarez, lo urbano, el hacinamiento y la destrucción del paisaje natural son parte de los intereses de los nuevos figurativos: 
Revista Herencia, Vol. 34 (2), enero-junio, 2021.

Lo urbano, lo rural, el hacinamiento, la contaminación, la destrucción del paisaje vienen a ocupar el espacio reflexivo de los artistas. Nace en ellos una necesidad de reconstruirlo, ya no en la forma poetizada que los paisajistas que el Círculo de Bellas Artes y la Escuela de Caracas lo hicieron; ahora los "neopaisajistas" fijan su atención en la carga emotiva que puede contener un paisaje, considerándolo, por esta razón, un personaje que emerge de la realidad palpable y de la imaginación del que crea una obra de este género. Así pues, podemos decir que la naturaleza está humanizada por el artista (2009, p. 101).

Como se deduce de lo anterior, el interés en el paisaje urbano no es solo la representación; es en tanto mecanismo reflexivo para interpretar la emotividad del paisaje humanizado. De esta manera, es posible establecer cierto paralelismo con la pintura en estudio, pues no solo plantea un nuevo paisaje urbano-marginal, sino que proyecta en esta la crítica social. De manera metonímica, incorpora al hombre y su realidad (cultura de la pobreza), siendo un paisaje sin humanos pero humanizado. Por lo tanto, es posible interpretar la obra Tugurios como un trabajo neofigurativo, en tanto incorpora el paisaje urbano como manifestación del ser.

Por otra parte, el artista neofigurativo se inquieta por el deterioro del paisaje natural. Esto hace que se llegue a la representación de un paisaje inventado; no pretende el realismo (en el sentido de copia) en la pintura, sino que construye reminiscencias de la realidad y del paisaje humanizado que finalmente crea:

Del artista brota la preocupación por el destino del paisaje natural, por el desgaste, deterioro y abandono al que ha sido sometido por el hombre. Es de esta preocupación que nace el "Nuevo Paisaje", que rompe con los esquemas del paisaje tradicional y que cambia los modos de ver la naturaleza. [...] Este nuevo paisajismo no representa el mundo, de manera rigurosamente realista; son paisajes inventados que muchas veces surgen del recuerdo del artista y que vienen a constituir reminiscencias entre la realidad y la fantasía (Tabárez, 2009, p. 100).

Si bien la intención de los artistas neofigurativos venezolanos es la representación no imitativa del nuevo paisaje, motivado por su preocupación ante el paisaje natural, se puede 
Revista Herencia, Vol. 34 (2), enero-junio, 2021.

establecer una diferencia con la obra Tugurios: esta no plantea precisamente ningún tipo de inquietud por el entorno natural; por el contrario, su interés es el estado social. Sin embargo, la obra en estudio representa una imagen poco realista, pues las casuchas de madera alcanzan solidez plástica y expresión artística; al igual que el paisaje neofigurativo mencionado, el cual posee paisajes inventados que muchas veces surgen del recuerdo del artista. De esta manera, Tugurios llega a ser una reminiscencia entre la realidad contextual del país y la interpretación que la obra hace del nuevo paisaje urbano en Costa Rica.

Por lo tanto, es posible establecer vínculos técnico-pictóricos, sígnicos, temáticos y contextuales entre la obra Tugurios y la estética neofigurativa. Esto corrobora no solo la existencia de la neofiguración en el país, sino que determina de qué manera y cómo se caracteriza esta tendencia en la pintura de paisaje urbano de Rafael Ángel Felo García. Con esto, se puede conocer y precisar el surgimiento de este movimiento en la pintura costarricense.

\section{Conclusiones}

El estudio de la pintura Tugurios permite observar un retorno a la representación figurativa posterior a obras no-figurativas, asimismo, este permite determinar ciertas características que establecen las particularidades plásticas, tanto técnicas como en su semántica. Por otra parte, el estudio permite establecer una contextualización de la obra, comprendido para el periodo de los Salones de Artes Plásticas (1972). En este sentido, dicho estudio consigue comprobar las características plásticas, semánticas y pragmáticas de un nuevo periodo figurativo en el arte costarricense.

En la obra pictórica Tugurios la composición y las representaciones de cables de luz, antenas de televisión y ropa tendida sobre las casas, exponen esa reintroducción de la figuración, por lo tanto, la obra representa un retorno a la pintura figurativa. Esto se estima como una 
Revista Herencia, Vol. 34 (2), enero-junio, 2021.

particularidad del arte neofigurativo, pues requiere de la existencia de la no-figuración para generar un regreso al trabajo representacional.

Por otra parte, al analizar el plano de la expresión en la obra (determinando la técnica como los semas que dan sentido a la pintura). Es posible observar cómo la obra representa una reutilización técnica de la no-figuración dentro de la nueva figuración, lo que se considera como otra característica de las obras neofigurativas. En el caso de Tugurios, en recursos técnicos como son el frotado, las texturas visuales y táctiles, se percibe la incorporación técnica del expresionismo ejercido por García (aplicado en el nuevo paisaje urbano). Esto posibilita interpretar un parentesco entre las representaciones pictóricas con el movimiento neofigurativo.

En el estudio del plano del contenido, se posibilita observar particularidades sígnicas en la obra que se enlazar fuertemente con el contexto y, a su vez, esto permite relacionar la obra con el movimiento pictórico neofigurativo. En este sentido, el estudio de los significados en Tugurios se interpreta como un germen social, ya que logra representa la realidad costarricense de los años setenta. La obra consiente interpretar significantes como las chozas y las otras representaciones, como isotopías de la misma temática de la pobreza, comprendiendo un nuevo paisaje urbano marginal. Esto se descubre como un signo de crítica social. También, a esto es posible estudiar los cromemas gris y blanco como referentes de esa cultura de la pobreza, así como el entendido metonímico del hombre y su crecimiento desmedido (ropa tendida). Esto hace factible entender la obra como de carácter neofigurativa, pues el interés primario de la neofiguración tiene que ver con temáticas sobre el ser humano y su entorno, como revela el estudioso Marchán Fiz.

Por otra parte, cuando se considera el contexto de la obra en estudio, se genera un vínculo entre el estudio de la obra y la realidad socio-cultural que representan, como unidad espacio-temporal. Es decir, la obra representa semánticamente una realidad contextual, la cual evidencia no solo la historia social sino artística de la Costa Rica de los años setenta. 
Revista Herencia, Vol. 34 (2), enero-junio, 2021.

Asimismo, hace factible interpretar esta correspondencia semántica-contextual como paradigma de la neofiguración en el país.

Para el contexto latinoamericano, la sociedad es influenciada por otras culturas a través de la llegada de la globalización y el neoliberalismo. Asimismo, el contexto costarricense de los años setenta se presenta como una época de cambio, esto se manifiesta en un creciente desarrollo industrial, el crecimiento de las ciudades, así como por la expulsión del campesino empobrecido. Estos cambios son percibidos como crisis de valores; pero no es comprendido como un problema -por algunos estudiosos-, sino como la expresión de una permutación en la ideología del ser costarricense, como un cambio de paradigma social.

Según lo anterior, dichos cambios se hacen visibles al observar el crecimiento de la ciudad y su posterior afeamiento, suceso generado por la migración campo-ciudad, lo cual estimula el crecimiento urbano. Este proceso urbanístico, concerniente al crecimiento de la población, es representado en Tugurios de Rafael Ángel Felo García con la proliferación de ropa tendida blanca; la obra se apropia de la metonimia para integrar al hombre y su realidad empobrecida. De esta manera, no solo se plantea un nuevo paisaje urbanomarginal, sino que se presenta la crítica social de la época.

Además, el estudio posibilita interpretar la representación, la técnica, la simbología y el contexto como equivalentes al movimiento neofigurativo presentado en la historia del arte posterior a los años sesentas, a través de los tres niveles (sintáctico, semántico y pragmático). Lo cual permite identificar y caracterizar al movimiento neofigurativo costarricense.

La representación poco realista del nuevo paisaje costarricense en Tugurios, con sus casuchas de madera representadas a través de la mancha, la textura y el frotado, trabajados con gran similitud al expresionismo de Rafael Ángel Felo García, permiten interpretar como la nueva figuración y la técnica se emparentan con trabajo pictórico las obras neofigurativas. Asimismo, la semántica de la estética del tugurio en Tugurios permiten observar un mismo 
Revista Herencia, Vol. 34 (2), enero-junio, 2021.

significado social, que se interpretan como crítica social, connotaciones propias de la neofiguración. Por tanto, esto se expone como una evocación de la realidad contextual de Costa Rica; esta relación obra-contexto también permite determinar una analogía con la propuesta neofigurativa, pues es parte de los cometidos de la tendencia.

En conclusión, aunado a la comprensión del trabajo pictórico Tugurios como ulterior a los años sesentas y posterior a la finalización del periodo no-figurativo en el país (1971), es que al estudiar el retorno de la figuración, la combinación técnica, la semántica, así como la relación contextual de la obra, es posible determinar una aproximación a la propuesta neofigurativa. Lo cual determina la valoración de la pintura como precursora del movimiento neofigurativo costarricense. 
Revista Herencia, Vol. 34 (2), enero-junio, 2021.

\section{BIBLIOGRAFÍA}

Alvarado Venegas, I., Barquero Segura, E. y Quirós, L. F. (2005). Felo García: artista, gestor, innovador. San José: Editorial de la Universidad de Costa Rica: Fundación Museos Banco Central de Costa Rica.

Barthes, R. (1987). El susurro del lenguaje: más allá de la palabra y la escritura. Barcelona: Ediciones Paidós.

Carrere, A. y Saborit, J. (2000). Retórica de la pintura. Madrid: Editorial Cátedra.

Deneb, L. (2001). Diccionario de símbolos: selección temática de los símbolos más universales. Madrid: Editorial Biblioteca Nueva.

Foucault, M. (2010). ¿Qué es un autor? Córdoba: Ediciones Literales.

Kowzan, T. (1997). El signo y el teatro. Madrid: Editores Arco.

Marchán Fiz, S. (2012). Del arte objetual al arte de concepto (11.a ed.) Madrid: Ediciones Akal. 
Revista Herencia, Vol. 34 (2), enero-junio, 2021.

Molina Jiménez, I. (2005). Costa Rica del siglo XX al XXI. Historia de una sociedad. San José: Editorial de la Universidad de Costa Rica.

Molina Jiménez, I. (2007). Identidad nacional y cambio cultural en Costa Rica durante la segunda mitad del siglo XX. San José: Editorial de la Universidad de Costa Rica.

Real Academia Española. (2001). Diccionario de la Real Academia Española. 22 ed. Vol. 2. Tomo 2, 4, 5, 6, 7, 9 y 10. Colombia: ESPASA.

Rojas González, J. M. (1994). Salones Nacionales de Artes Plásticas 1972-1993: programa re-visión de un siglo. San José: Museo de Arte Costarricense.

Talens, J., Romera Castillo, J., Tordera, A. y Vicente Hernández, E. (1999). Elementos para una semiótica del texto artístico. Madrid: Cátedra.

Tamburrino Cabrera, E. (2008). Análisis crítico descriptivo de la nueva figuración argentina 1961-1965. Ernesto Deira, Rómulo Macció, Jorge de la Vega y Luis Felipe Noé. (Tesis de Licenciado en Artes con mención en Teoría e Historia del Arte). Universidad de Chile.

Ulloa Barrenechea, R. (1979). Pintores de Costa Rica. San José: EUCR. 
Revista Herencia, Vol. 34 (2), enero-junio, 2021.

\section{PUBLICACIONES PERIÓDICAS}

Alvarado Venegas, lleana. (2011). Felo García y la representación de la arquitectura marginal. Revista Comunicación, 20(1), Instituto Tecnológico de Costa Rica, Cartago, enero-junio, 67-74.

Zavaleta-Ochoa, Eugenia. (1993). Gestación del arte abstracto en Costa Rica. Káñina. Revista de artes y letras. 17(2), 245-265.

\section{REFERENCIAS ELECTRÓNICAS}

Alvarado-Venegas, Ileana. (2011). Felo García y la representación de la arquitectura marginal. Comunicación, Instituto Tecnológico de Costa Rica. Año 32, 20(1). http://revistas.tec.ac.cr/index.php/comunicacion/article/view/826/740 [Consulta 1710 jun. 2015].

Tabárez-Reyes, Nidia. 2009. Esbozo histórico del arte de representación en paisajes en Venezuela desde principios hasta fines del siglo XX. Tiempo y Espacio [online], 19(51),

89-110.

http://www.scielo.org.ve/scielo.php?script=sci_arttext\&pid=S1315-

94962009000100006 [Consulta 20 may. 2016]. 
Revista Herencia, Vol. 34 (2), enero-junio, 2021.

Triana-Cambronero, María Alejandra. (2013). Las tramas de Felo García. La Nación Áncora. http://wfnode01.nacion.com/2010-10-

31/Ancora/NotasSecundarias/Ancora2537543.aspx [Consulta 06 may. 2015]. 
Revista Herencia, Vol. 34 (2), enero-junio, 2021. 